\title{
Twin Rectal Tonsils Mimicking Carcinoid or Mucosa-Associated Lymphoid Tissue Lymphoma
}

\author{
Masanori Takehara', Naoki Muguruma ${ }^{1}$, Shinji Kitamura ${ }^{1}$, Tetsuo Kimura ${ }^{1}$, Koichi Okamoto ${ }^{1}$, Hiroshi Miyamoto ${ }^{1}$, Yoshimi Bando ${ }^{2}$ \\ and Tetsuji Takayama ${ }^{1}$ \\ ${ }^{1}$ Department of Gastroenterology and Oncology, Tokushima University Graduate School of Biomedical Sciences, ${ }^{2}$ Division of Pathology, \\ Tokushima University Hospital, Tokushima, Japan
}

The rectal tonsil is a rare polypoid lesion exclusively found in the rectum and is considered a reactive proliferation of the lymphoid tissue. Although this lesion is benign, we recommend that it should be differentiated from carcinoid or polypoid type of mucosaassociated lymphoid tissue lymphomas, based on gross findings. In this case report, we describe a case of rectal lesions with a unique appearance in a 41-year-old man. Colonoscopy revealed two 5-mm-sized nodules located opposite from each other on the left and right sides of the lower rectum. Endoscopic mucosal resection was conducted. Histopathologically, both lesions were mainly located in the submucosa and consisted of prominent lymphoid follicles with germinal centers of various sizes. No immunoreactivity of Bcl2 was seen in the germinal centers. Immunohistochemical staining for kappa and lambda light chains revealed a polyclonal pattern. Therefore, these lesions were diagnosed as rectal tonsils. Clin Endosc 2017;50:500-503

Key Words: Lymphoid hyperplasia; Rectal neoplasia; Submucosal tumor; Endoscopic procedure; Histopathology

\section{INTRODUCTION}

Localized lymphoid hyperplasia of the large intestine is rare and appears exclusively in the rectum. ${ }^{1,2}$ This lesion is also known as lymphoid polyp, benign lymphoid polyp, and rectal tonsil. ${ }^{3,4}$ Although an association with infections such as chlamydia or Epstein-Barr virus has been reported, ${ }^{5,6}$ its etiology remains unknown. Since rectal tonsils are benign, we recommend it should be differentiated from other lymphomas such as carcinoids or the polypoid type of mucosa-associated lymphoid tissue (MALT) lymphomas due to its similarity to these tumors upon gross examination. ${ }^{1,7,8}$ In

Received: November 15, 2016 Revised: December 12, 2016

Accepted: December 15, 2016

Correspondence: Naoki Muguruma

Department of Gastroenterology and Oncology, Tokushima University Graduate School of Biomedical Sciences, 3-18-15 Kuramoto, Tokushima 770-8503, Japan

Tel: +81-88-633-7124, Fax: +81-88-633-9235, E-mail: muguruma.clin.med@gmail.com

(cc) This is an Open Access article distributed under the terms of the Creative Commons Attribution Non-Commercial License (http://creativecommons.org/ licenses/by-nc/3.0) which permits unrestricted non-commercial use, distribution, and reproduction in any medium, provided the original work is properly cited. this report, we describe a case of twin rectal tonsils that was diagnosed by immunohistochemistry following endoscopic mucosal resection.

\section{CASE REPORT}

A 41-year-old man with a long history of psoriasis, and was taking $150 \mathrm{mg}$ of oral cyclosporine daily and using a topical steroid medication, underwent a computed tomography (CT) scan as a systemic screening for the administration of anti-tumor necrosis factor (TNF)-alpha antibodies. He was referred to our department for further evaluation after an increased density of mesenteric adipose tissue was revealed in his abdomen. His past medical history was unremarkable except the skin disease, and laboratory data showed no other abnormalities. Colonoscopy in retroflexed view revealed two 5 -mm-sized nodules that were identical in appearance and were located opposite of each other on the left and right sides of the lower rectum (Fig. 1). These nodules were both slightly red in color, and observations by narrow-band imaging (NBI) 


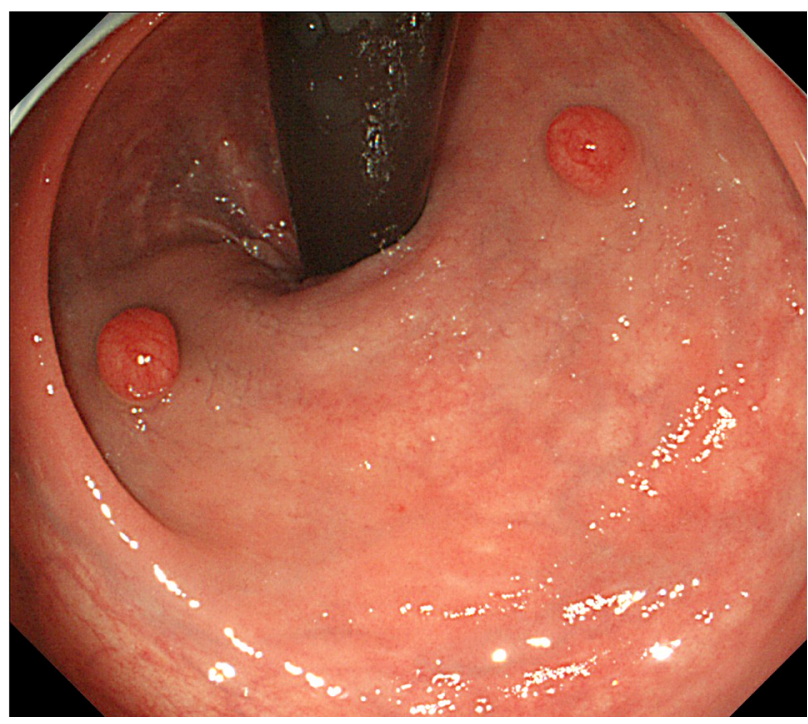

Fig. 1. Endoscopy revealed two red nodules (5 $\mathrm{mm}$ in size) located $15 \mathrm{~mm}$ from the anal verge. with magnification revealed dilated branches of vessels on the mucosal surface (Fig. 2A, B). Endoscopic ultrasound (EUS) revealed well-demarcated small hypoechoic areas in the lamina propria (Fig. 2C, D). We performed a biopsy but were unable to make a definitive final diagnosis due to the small tissue samples. Therefore, an endoscopic mucosal resection was conducted in order to make a more precise diagnosis and to remove the nodules. Histopathologically, both lesions were mainly located in the submucosa and consisted of prominent lymphoid follicles with germinal centers of various sizes (Fig. 3A). The polarization of the follicle and the presence of tingible body macrophages suggested a reactive rather than neoplastic follicular process. No immunoreactivity with Bcl-2 was observed in the germinal centers (Fig. 3B). Aggregates of CD20-positive lymphoid cells were distributed in the mucosa. Although small numbers of B cells were seen in the glands, epithelial destruction was not observed. Immunohistochemical staining for kappa and lambda light
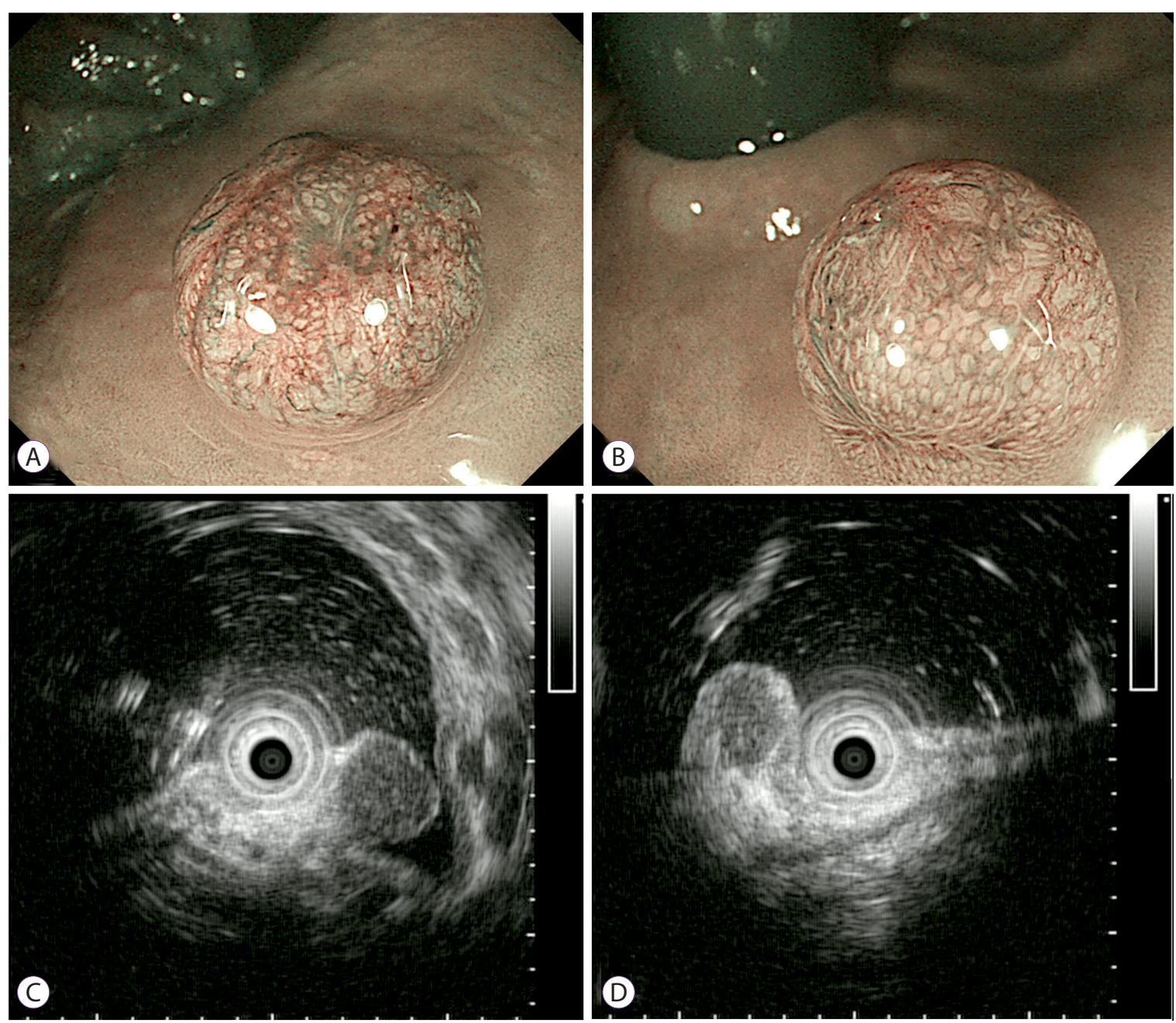

Fig. 2. Narrow-band imaging with magnification revealed dilated branches of vessels on the mucosal surface. (A) Left lesion, (B) Right lesion. Endoscopic ultrasound showed well-demarcated small hypoechoic areas in the lamina propria. (C) Left lesion, (D) Right lesion. 

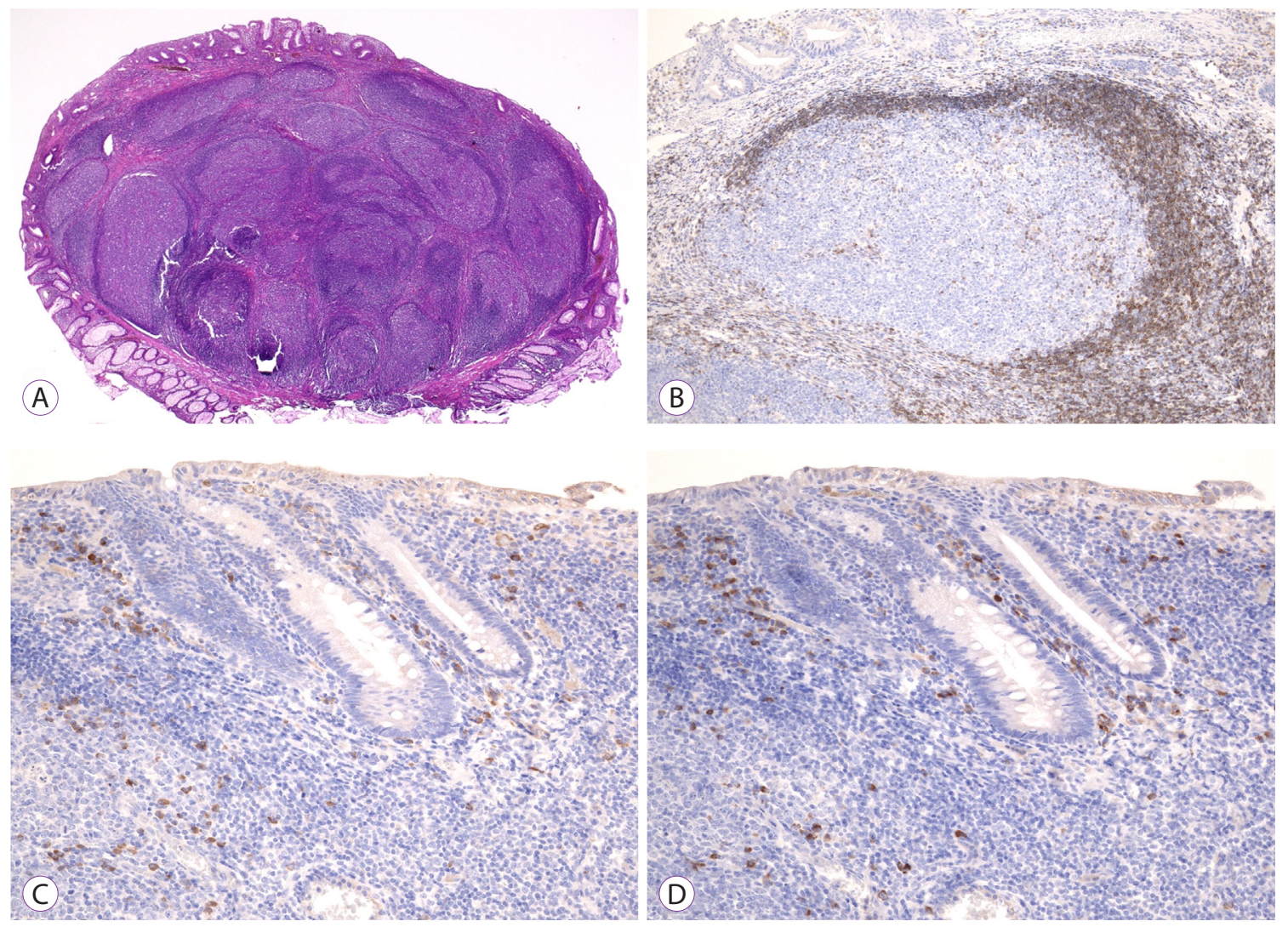

Fig. 3. Histopathological findings of endoscopic mucosal resection specimen. (A) Low power view with hematoxylin and eosin staining $(\times 20)$. Immunohistochemistry revealed that the cells were negative for $(\mathrm{B})$ bcl-2 $(\times 100)$ and $(\mathrm{C})$ kappa $(\times 200)$ and $(\mathrm{D})$ lambda $(\times 200)$ light chains showed a polyclonal pattern.

Table 1. Summary of Reported Rectal Tonsil

\begin{tabular}{|c|c|c|c|c|c|}
\hline Study & Case & $\operatorname{Sex}(M / F)$ & Mean age (range) & Endoscopic appearance $(n)$ & Size $(\mathrm{mm})$ \\
\hline Kojima et al. $(2005)^{1}$ & 3 & $0 / 3$ & $59(46-66)$ & Solitary sessile (1), Multiple sessile (2) & $5-6$ \\
\hline Kojima et al. $(2007)^{2}$ & 2 & $0 / 2$ & $61(50-71)$ & Solitary sessile (2) & $5-6$ \\
\hline Farris et al. $(2008)^{7}$ & 11 & $6 / 5$ & $49(1-62)$ & Polyp (8), Nodules (2), Mass (1) & $3-12$ \\
\hline Eire et al. $(2011)^{9}$ & 1 & $0 / 1$ & 4 & Nodular & 30 \\
\hline Homan et al. $(2012)^{10}$ & 1 & $0 / 1$ & 6 & Sessile & - \\
\hline Grube-Pagola et al. $(2012)^{5}$ & 1 & $1 / 0$ & 58 & Nodular & $40 \times 30 \times 30$ \\
\hline Hong et al. $(2015)^{8}$ & 1 & $0 / 1$ & 59 & Solitary sessile & 5 \\
\hline Our case & 1 & $1 / 0$ & 41 & Nodules & 5 \\
\hline
\end{tabular}

chains revealed a polyclonal pattern (Fig. 3C, D). Therefore, these lesions were diagnosed as rectal tonsils with no malignancy.

\section{DISCUSSION}

Since 2005, 21 cases of rectal tonsil, including ours, have been reported in the scientific literature ${ }^{1,2,5,7-10}$ (Table 1). These cases comprised 8 males and 13 females aged 1-71 years. Four of the 21 cases presented with multiple lesions.
Although the endoscopic appearance of rectal tonsils varies among types such as polypoid (38\%), sessile (33\%), and nodule or mass (29\%), most rectal tonsils appear to be covered with a normal epithelium and present as submucosal lesions. While their conventional endoscopic and endosonographic appearance are somewhat similar to those of the rectal tonsil, carcinoid tumors more commonly appear as yellow-colored solitary lesions. These characteristics could be used as distinguishing features for diagnosing rectal tonsils. Although the nodules in our case demonstrated dilated branches of vessels on the mucosal surface under NBI with magnification, it re- 
mains unclear whether this finding is a characteristic of rectal tonsils. Additionally, in our case, there was a discrepancy in the location of the rectal tonsil as observed with EUS and histopathology. This may have been due to the shape of the lesion since a significant portion of it was protruding into the lamina propria. Therefore, accumulation of the rectal tonsil is needed for it to be observed under NBI with magnification and EUS.

Previous studies have also reported rectal tonsils that mimic lymphomas and MALT lymphomas. ${ }^{1,9}$ These lesions were diagnosed as rectal tonsils by endoscopic removal followed by immunohistochemistry. Histologically, rectal tonsils are characterized by large lymphoid follicles accompanied with active germinal centers in the submucosa. No colonized lymphoid follicles or lymphoepithelial lesions (LELs) have been reported in rectal tonsils. The diagnosis of MALT lymphomas is usually based on histopathological morphology such as a prominent marginal zone and the presence of LELs. Immunohistochemical monoclonality including CD43 and/or the presence of immunoglobulin light chain restrictions are also characteristics of MALT. ${ }^{1}$ Our present case demonstrated polyclonal reactivity for kappa and lambda light chains and a lack of Bcl-2 staining in the follicles. Based on these findings, MALT and follicular lymphoma were excluded in the diagnosis.

In conclusion, rectal tonsils are a benign reactive change, although it is similar in endoscopic appearance to carcinoids, MALTs, or follicular lymphomas. In a superficial or small biopsy, rectal tonsils can be incorrectly diagnosed as malignant lymphomas. For an appropriate diagnosis and treatment of rectal tonsils, complete resection by endoscopy, histopatho- logical examination, and immunohistochemical evaluations are recommended. ${ }^{1,5}$

Conflicts of Interest

The authors have no financial conflicts of interest.

\section{REFERENCES}

1. Kojima M, Itoh H, Motegi A, Sakata N, Masawa N. Localized lymphoid hyperplasia of the rectum resembling polypoid mucosa-associated lymphoid tissue lymphoma: a report of three cases. Pathol Res Pract 2005;201:757-761.

2. Kojima M, Iijima M, Shimizu K, Hoshi K. Localized lymphoid hyperplasia of the rectum representing progressive transformation of the germinal center. A report of two cases. APMIS 2007;115:1432-1436.

3. Ranchod M, Lewin KJ, Dorfman RF. Lymphoid hyperplasia of the gastrointestinal tract. A study of 26 cases and review of the literature. Am J Surg Pathol 1978;2:383-400.

4. Cornes JS, Wallace MH, Morson BC. Benign lymphomas of the rectum and anal canal: a study of 100 cases. J Pathol Bacteriol 1961;82:371-382.

5. Grube-Pagola P, Canales-Kay A, Meixueiro-Daza A, Remes-Troche JM. Rectal tonsil associated with Epstein-Barr virus. Endoscopy 2012;44 Suppl 2 UCTN:E388-E389.

6. Cramer SF, Romansky S, Hulbert B, Rauh S, Papp JR, Casiano-Colon AE. The rectal tonsil: a reaction to chlamydial infection? Am J Surg Pathol 2009;33:483-485.

7. Farris AB, Lauwers GY, Ferry JA, Zukerberg LR. The rectal tonsil: a reactive lymphoid proliferation that may mimic lymphoma. Am J Surg Pathol 2008;32:1075-1079.

8. Hong JB, Kim HW, Kang DH, et al. Rectal tonsil: a case report and literature review. World J Gastroenterol 2015;21:2563-2567.

9. Eire PF, Victoria RF, Castañón AI, Arias MP, Carril AL, Burriel JI. The rectal tonsil in children: a reactive lymphoid proliferation that may mimic a lymphoma. Indian J Gastroenterol 2011;30:282-283.

10. Homan M, Volavšek M. Rectal tonsil. J Pediatr Gastroenterol Nutr 2012;54:575. 